\title{
Small Molecular Drug Transfer across the Blood-Brain Barrier via Carrier-Mediated Transport Systems
}

\author{
Akira Tsuji \\ Division of Pharmaceutical Sciences, Graduate School of Natural Science and Technology, Kanazawa University, \\ Kakuma-machi, Kanazawa 920-1192, Japan
}

Summary: Because of the physiological nature of the bloodbrain barrier (BBB), transport of chemical compounds between blood and brain has been widely believed to occur by means of passive diffusion, depending upon the lipophilicity of the compounds. However, discrepancies exist between the lipophilicity and apparent BBB permeation properties in many cases, and these discrepancies can be ascribed to the existence of multiple mechanisms of drug transport through the BBB. Molecular identification and functional analysis of influx transport proteins (from blood to brain) and efflux transport proteins (from brain to blood) have progressed rapidly. Therefore, the BBB is now considered to be a dynamic interface that controls the influx and efflux of a wide variety of substances, including endogenous nutrients and exogenous compounds such as drugs, to maintain a favorable environment for the CNS. This review focuses on the role of transport systems in the uptake of xenobiotics, including organic anionic/cationic and neutral drugs, across the $\mathrm{BBB}$ into the brain, as well as on strategies to increase drug delivery into the brain by blocking efflux transport protein function, or to reduce CNS side effects by modulating BBB transport processes. Key Words: Transporter, blood-brain barrier, influx transport, organic anions, organic cations, drug delivery.

\section{INTRODUCTION}

Transporters that mediate influx and efflux of endogenous nutrients and exogenous toxins including drugs across biological membranes are necessary for the survival of mammalian species. These transporters are classified into the solute carrier superfamily, for which gene symbols are prefixed with $S L C$, and ATP binding cassette transporters, for which gene symbols are prefixed with $A B C$ (http:// www.gene.ucl.ac.uk/nomenclature/genefamily.shtml).

The CNS contains cellular barriers that maintain homeostasis by elimination of toxic metabolites generated in the brain. The barriers that limit the concentrations of toxins and xenobiotics in the interstitial fluids of the CNS are the blood-brain barrier (BBB), consisting of brain capillary endothelial cells, and the blood-CSF barrier, consisting of epithelial cells. Both barriers have cellular tight junctions and express transport systems that serve to actively transport physiologically important nutrients such as glucose, amino acids, etc. into the brain, and to

Address correspondence and reprint requests to Professor Akira Tsuji, Ph.D., Division of Pharmaceutical Sciences, Graduate School of Natural Science and Technology, Kanazawa University, Kakuma-machi, Kanazawa 920-1192, Japan. E-mail: tsuji@kenroku.kanazawa-u.ac.jp. actively import or export various xenobiotics including drugs and their metabolites. These transport systems are increasingly being recognized as important determinants of drug distribution into and efflux from the brain.

The present review is focused on influx, but not efflux, transporters that have been identified at the molecular level and have relevance to drug delivery to the brain, especially the SCL transporters and related transport systems expressed in the BBB.

\section{Carrier-mediated transport of amino acid-like drugs}

Essential amino acids need to be transferred from the bloodstream to the brain, and the presence of specific transporters has been documented. ${ }^{1}$ Transporters for amino acids have in general been classified in terms of their functional characteristics such as sodium dependence and substrate specificity. Large neutral amino acids such as phenylalanine, tyrosine, and leucine are transported by System L across the BBB in a sodium-ion-independent manner, and this system is characterized by specific reduction of its activity by 2-aminobicyclo2,2,1-heptane-2-carboxylic acid (BCH). ${ }^{1}$ This system is supposed to be important for drug delivery because System L has broad substrate 
specificity for relatively large molecules. System L is presumed to transport CNS-acting drugs such as levodopa, baclofen, and gabapentin across the BBB. ${ }^{1,2}$ The in vivo significance of System $\mathrm{L}$ in levodopa transport across the BBB was indirectly shown by the decreased effectiveness of levodopa after a protein-rich meal in humans. ${ }^{3}$ The decrease in pharmacological activity was explained in terms of lowered distribution of levodopa into the brain due to saturation of System L with high plasma concentrations of amino acids generated from the meal. ${ }^{3}$ Recently, one of the System L transporter genes has been cloned and named LAT-1 (SLC7A5). ${ }^{4,5}$ LAT-1 is characterized by sodium-ion independence with Michaelis constant $(\mathrm{Km})$ values varying from $10 \mu \mathrm{M}$ order for leucine to $1 \mathrm{~mm}$ order for glutamine, depending on the hydrophobicity and side-chain conformation of the amino acids. ${ }^{6}$ LAT- 1 is highly expressed at the BBB and requires coexpression with cell surface glycoprotein $4 \mathrm{~F} 2$ heavy chain to be adequately expressed on the cell membrane surface. ${ }^{4-7}$

LAT-2 (SLC7A8), which shows differential substrate specificity from LAT-1, may also function as a transporter for amino acids and drugs at the BBB. ${ }^{8-10}$

\section{Hexose transport systems}

Glucose is essential for brain function and glucose crosses the BBB via a specific transporter. Because the capacity of the glucose transporter at the BBB is significantly higher $(1420 \mathrm{nmol} / \mathrm{min} \cdot \mathrm{g}$ tissue $)$ than those of other nutrient transporters $(91 \mathrm{nmol} / \mathrm{min} \cdot \mathrm{g}$ tissue for monocarboxylic acid, 28 for neutral amino acid and 11.3 for amine transport systems), it is expected to be applicable for the brain delivery of drugs. ${ }^{11}$ There are two types of glucose transporters, namely sodium-dependent (secondary active) and -independent (facilitative) transporters that are molecularly classified into the SGLT (SLC5A) and GLUT (SLC2A) families, respectively. Sodium-independent glucose transporters are thought to be functional in the brain, although the possible involvement of members of the SGLT transporter family cannot be completely excluded. ${ }^{12}$ Sodium-independent GLUT1 (SLC2A1) transporter is present at brain capillaries, as well as choroid plexus and neuronal cell membranes. Interestingly, the glycosylation state of GLUT1 is variable among regions, resulting in different molecular masses of 54, 47, and $42 \mathrm{kDa}$ in brain capillaries, choroid plexus and neuronal cells, respectively. ${ }^{13}$ Although further molecular studies on glucose transport at the BBB are needed, the glucose transporter is likely to be useful for delivery of membrane-impermeable compounds, and several authors have found that sugar analogues may cross the barrier via this transporter. Modification of D-glucose with an $O$-methylsulfonyl moiety was tried for delivery of the alkylating agent busulfan into the brain. ${ }^{14}$ Furthermore, glycosylation of the opioid peptide dermor- phin was tried. ${ }^{15}$ In the case of peptide compounds, glycosylation may stabilize the peptides, rather than enhance the BBB permeability. More studies are needed on the utilization of the glucose transporter to obtain enhanced permeability across the BBB.

\section{Monocarboxylate transport family}

Lactic acid and other monocarboxylates are important metabolic products and energy substrates of brain metabolism in mammalians, and their movement across the BBB is regulated by specific uptake and efflux transporters. The carrier-mediated transport system for these drugs is presumably common to short-chain fatty acids such as acetate. ${ }^{16,17}$

Earlier in vivo studies suggested the presence of a monocarboxylate transport (MCT) system at the BBB as demonstrated by stereospecific and saturable transport of lactate and pyruvate across the BBB. ${ }^{18-20}$ Other in vivo studies in our laboratories indicated that several compounds including acetate, propionate, butyrate, benzoic acid, salicylic acid, nicotinic acid, and some $\beta$-lactam antibiotics may be transported by the MCT at the BBB. ${ }^{21}$ Numerous studies using primary cultured brain capillary endothelial cells as an in vitro BBB model support these in vivo results. ${ }^{22,23}$

Currently, at least eight members of the MCT (SLC16A) family have been discovered in various tissues and orthologs to each have been identified in a variety of species. ${ }^{24}$ Each isoform possesses unique biochemical properties, such as kinetic constants and sensitivity to MCT inhibitors. Post-translational regulation of MCT1 (SCL16A1) and MCT4 (SLC16A3) occurs, in part, by interaction with CD147, an accessory protein that is necessary for trafficking, localization, and functional expression of these transporters. ${ }^{24}$

Among MCT family members, MCT1 is expressed in the epithelium of the small intestine and colon, the BBB and other tissues, including muscle. MCT1 expressed at the BBB is likely to provide a mechanism for the bloodto-brain and brain-to-blood transfers of carboxylated pharmaceutical agents and other exogenous monocarboxylates. Rat MCT1 stably expressed in cultured MDAMB231 cells exhibited pH-dependent, stereospecific transport of lactic acid and R- and S-mandelic acid, ${ }^{25}$ as observed previously in the transport of pyruvic acid by MCT1 in Chinese hamster ovary (CHO) cells. ${ }^{26}$ Interestingly, benzoic acid, which had long been believed to cross membranes by passive diffusion according to the $\mathrm{pH}$ partition hypothesis, is a good substrate ${ }^{25}$ for rat MCT1. Transport of benzoic acid across the BBB studied by using primary cultured cells of rat brain capillary endothelial cells (RBEC1) and by the in vivo Brain Uptake Index (BUI) method exhibited Km values comparable with that in MCT1-transfected cells. In addition, 


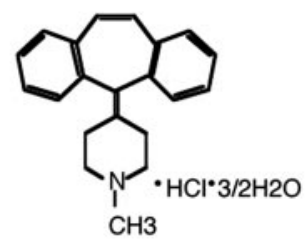

Cyproheptadine

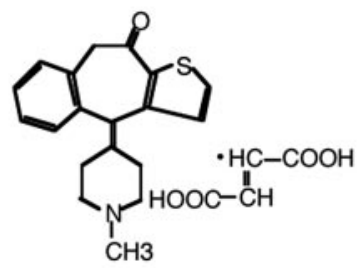

Ketotifen fumarate

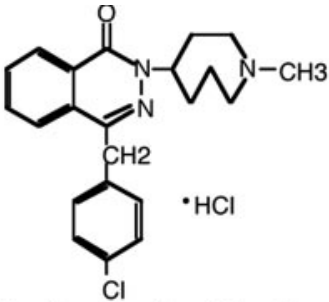

Azelastine hydrochloride

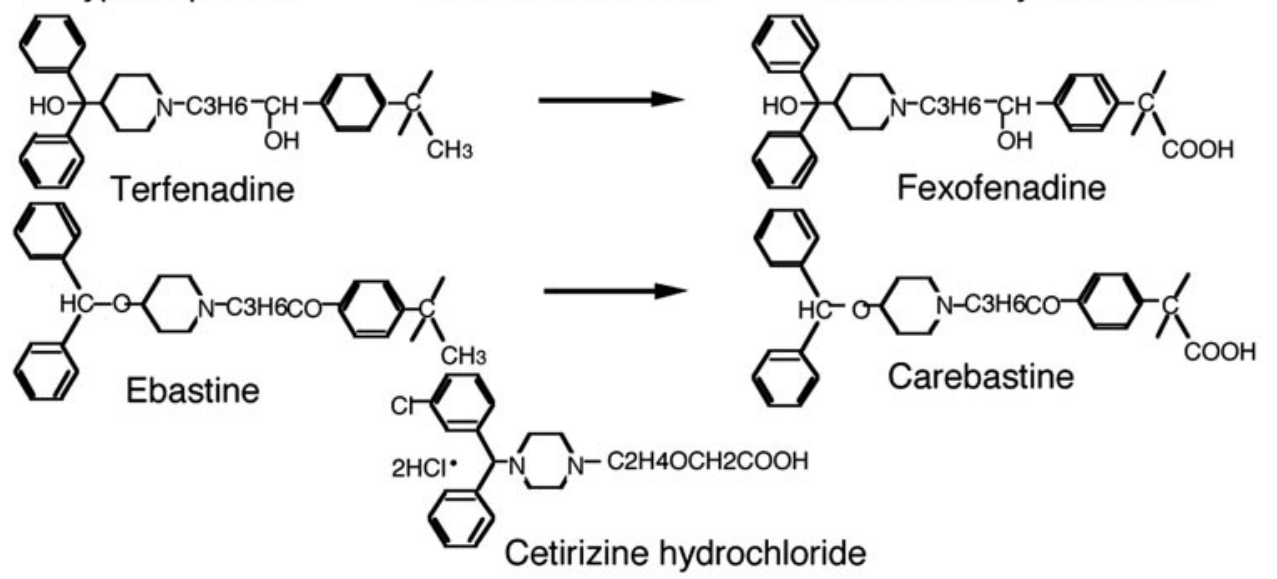

FIG. 1. Chemical structures of $\mathrm{H} 1$ antagonists.

pH dependence, substrate specificity, and stereospecificity were comparable in all four experimental systems. Furthermore, when expression of MCT1 in RBEC1 cells was depressed by transfection of an antisense oligonucleotide against rat MCT1, the uptake of benzoic acid was abrogated. ${ }^{17}$ These observations demonstrate that MCT1 is responsible for monocarboxylate transport at the BBB. MCT1 is likely to transport relatively small molecules having a monocarboxylate moiety and with a molecular weight of up to $\sim 200$.

Immunoblotting. immunohistochemical, and electron micrographic techniques using MCT1-specific antibodies have shown that MCT1 is expressed on the luminal and abluminal membranes of brain capillary endothelial cells, and the expression seen in sucking rat brain is much stronger than that in adults. MCT1 may be responsible for the transport of some organic anions from brain to endothelial cells and/or from endothelial cells to blood, because it is expressed on both the luminal and abluminal membranes of brain capillary endothelial cells, and it seems to operate bidirectionally. ${ }^{16,24,25}$ It is also possible that lactic acid and other monocarboxylates are excluded from the brain via the abluminal MCT1 to maintain homeostasis. ${ }^{24}$ Microdialysis studies of probenecid in the rat brain interstitial fluid suggest that the restricted distribution of probenecid ${ }^{27}$ and 6-mercaptopurine $^{28}$ in the brain is the result in part of efflux via MCT1, as well as a contribution by MRP2 and organic anion transporters that are known to be expressed at the BBB. $^{29}$

There are several studies showing that an anticonvul- sant, valproic acid, is efficiently transported across the BBB. ${ }^{30,31}$ When uptake of valproic acid was measured by an in situ brain perfusion method, it was saturable, with $\mathrm{Km}$ values between 10 and $20 \mathrm{~mm}$, depending on the measured brain regions. Uptake of valproic acid was reduced in the presence of medium-chain fatty acids such as hexanoate, octanoate, and decanoate, but not propionate or butyrate, indicating that valproic acid is taken up into the brain via a transport system for medium-chain fatty acids, not short-chain fatty acids. Interestingly, acetic acid, probenecid, and dicarboxylic acids, such as succinate and glutarate, increased the brain uptake of valproic acid. ${ }^{27}$ These observations may be ascribed to participation of an anion exchange mechanism similar to that reported for renal transport of organic anions such as $p$-aminohippuric acid, ${ }^{32}$ or to inhibition of efflux of valproic acid from brain to blood, or to some other indirect effect. Based on these reports, valproic acid is thought to be transported bidirectionally between blood and brain across the BBB via two distinct mechanisms, monocarboxylic acid-sensitive and medium-chain fatty acid-sensitive transporters, for efflux and uptake, respectively.

\section{Organic anion transporter family and organic anion transporting polypeptide transporter family}

Four mammalian organic anion transporter (OAT) isoforms (OAT1, OAT2, OAT3 and OAT4) have been identified. $^{33,34}$ OAT1 (SLC22A6) and/or OAT3 (SLC22A8) are likely to play the important roles in the transport of several organic anions in the brain. However, the localization of OATs in the brain is not clear. P-Aminohip- 
puric acid is a substrate of both rOAT1 and rOAT3 and is actively transported from brain to plasma across the BBB and so OATs are outside the scope of this review. Members of the multispecific organic anion transporting polypeptide superfamily, rOatp1 (Slc21al) and rOatp2 (Slc21a4) in rats and hOATP-A (SLC21A3) in human, have been reported to be expressed at the BBB. ${ }^{35,36}$ rOatp2 is expressed on both the luminal and abluminal membranes of brain capillary endothelial cells. ${ }^{37}$ In functional expression studies in Xenopus laevis oocytes, rOatp2 mediated the uptake of bile acids such as taurocholate $(\mathrm{Km}=35 \mu \mathrm{M})$ and cholate $(\mathrm{Km}=46 \mu \mathrm{M})$, estrogen conjugates such as $17 \beta$-estradiol-glucuronide $(\mathrm{Km}=0.24 \mu \mathrm{M})$, and cardiac glycosides such as ouabain $(\mathrm{Km}=470 \mu \mathrm{M})$ and digoxin $(\mathrm{Km}=0.24 \mu \mathrm{M}) .{ }^{37} \mathrm{Al}-$ though most of the compounds indicated above are common substrates of several rOatp-related transporters, high-affinity uptake of digoxin is a unique feature of rOatp2. It is well known that digoxin overdose induces several types of central nervous side effects. These results indicate that oatp2, which is highly expressed in brain, as well as liver and kidney, may play an especially important role in the brain accumulation and toxicity of digoxin and in the hepatobiliary and renal excretion of cardiac glycosides from the body. ${ }^{36}$ Recently, OATP-B (SLC21A9), which transports estrone-3-sulfate, ${ }^{38,39}$ has been reported to be expressed in brain capillary endothelial cells ${ }^{40}$ but not in the whole brain. ${ }^{38}$ OATP-B is also expressed in the liver and intestine. In the intestine, OATP-B expressed at the brush-border membrane of epithelial cells works effectively at the acidic microclimate $\mathrm{pH}$ (around 6), rather than at $\mathrm{pH} 7$, in the absorption direction for various compounds including taurocholate, estrone-3-sulfate, dehydroepiandrosterone-sulfate, pravastatin, and hexofenadine, ${ }^{41,42}$ Although the role in drug transport of OATP-B expressed at the BBB is unclear, lipophilic 3-hydroxy-3-methylglutaryl (HMG)-CoA reductase inhibitors such as the acid forms of simvastatin and lovastatin, which cause sleep disturbance as a CNS side effect, are likely to be transported via OATP-B even under a neutral $\mathrm{pH}$ condition. This speculation is based on previous observations from in vitro and in vivo $\mathrm{BBB}$ transport studies in our laboratory that the acid forms of simvastatin and lovastatin were taken up significantly via organic anion sensitive transport systems, but the BBB transport of pravastatin (having no significant CNS side effect) is negligible. ${ }^{43,44}$

\section{Organic cation transporter (OCT and OCTN) family}

Members of the organic cation transporter (OCT, $S L C 22 A$ ) family have been molecularly identified in the rat, rabbit, and human. ${ }^{45}$ They transport a variety of cationic compounds, including monoamine neurotransmitters, classical organic cation transporter substrates such as tetraethylammonium (TEA) and choline, neurotoxic 1-methyl-4-phenylpyridinium (MPP), and other cationic compounds. Rat OCT3 (SLC22A3) and human OCT2 (SLC22A2) are expressed in the brain, but it is thought that they participate in the regulation of neurotransmitters in neurons rather than at the BBB. ${ }^{46,47}$

We have isolated a new family of organic cation/ carnitine transporters, OCTNs (OCTN1-3) from human and mouse. ${ }^{48-50}$ OCTN2 (SLC22A5) was also cloned from rat intestine. ${ }^{51}$ The amino acid sequences of OCTN1 (SLC22A4), OCTN2 and OCTN3 show low but significant similarity to those of OCT family members and OCTNs were initially thought to be organic cation transporters. However, subsequent studies clarified that their physiological function was as sodium ion-dependent transporters for carnitine, which is important in the metabolism of fatty acids. ${ }^{52}$ Mutation of OCTN1 and OCTN2 have been reported to cause Crohn's disease ${ }^{53}$ and primary carnitine deficiency, ${ }^{52}$ respectively.

OCTN1 and OCTN2 transport organic cations such as TEA in a $\mathrm{pH}$-dependent or an $\mathrm{Na}^{+}$-independent manner. ${ }^{54-57}$ On the other hand, OCTN2 mediates carnitine transport in a $\mathrm{Na}^{+}$-dependent manner. ${ }^{49,50,56}$ OCTN2 mRNA is strongly expressed in human kidney, placenta, heart, and skeletal muscle, and weakly expressed in brain, lung, and liver. ${ }^{49,50,56}$ OCTN2 behaves as an exchange transporter in $\mathrm{Na}^{+}$-dependent carnitine reabsorption in the kidney and mediates $\mathrm{Na}^{+}$-independent secretion of organic cations. ${ }^{58}$ OCTN2 was confirmed to be expressed in primary cultured and freshly isolated brain capillary endothelial cells of mice, rats and humans. ${ }^{59,60}$ Freshly isolated brain capillary endothelial cells from Octn2 gene-deficient mice (jvs), when compared with those from normal mice exhibited a significant reduction of $\mathrm{Na}^{+}$-dependent carnitine transport. The brain-toplasma concentration ratio $(\mathrm{Kp})$ of carnitine after intravenous administration was demonstrated to be significantly decreased in jvs mice compared with that in normal mice. ${ }^{60}$ A very similar decrease of the Kp value of brain in jvs mice was observed for TEA, ${ }^{57,58}$ indicating that OCTN2 plays a significant role in BBB transport of some organic cations, as well as carnitine.

Although the significance of the organic-cation transport function of OCTN2 remains unknown, many organic cations recognized by OCTN2 as substrates are pharmacologically active and are currently used as therapeutic agents. ${ }^{58}$ By using jvs mice, we showed that mOCTN2 can work as an efflux transporter for intracellular TEA when extracellular carnitine is taken up into tubular cells in a $\mathrm{Na}^{+}$-dependent manner. ${ }^{58}$ Therefore, OCTN2 may play a significant role in the cellular uptake and/or efflux of therapeutically important organic cations in the body. 


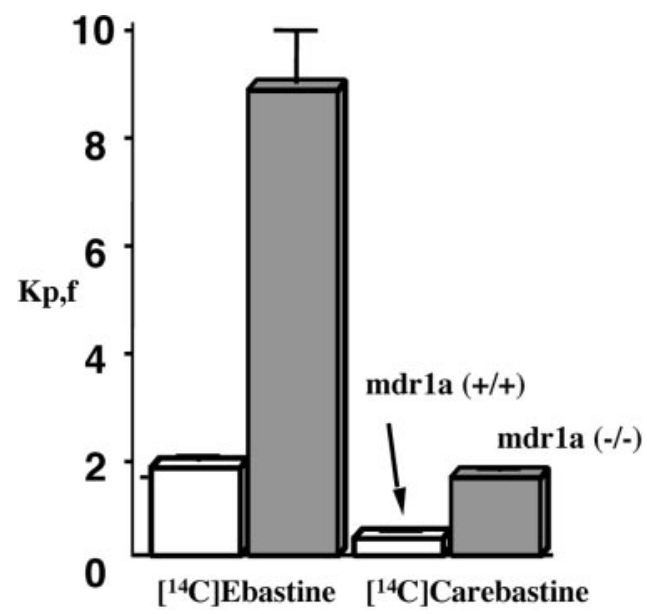

FIG. 2. Brain-to-plasma free concentration ratios of $\left[{ }^{14} \mathrm{C}\right]$ ebastine and $\left[{ }^{14} \mathrm{C}\right]$ carebastine 6 min after intravenous administration to wild-type mice $[\mathrm{mdr} 1 \mathrm{a}(+/+)]$ and to mdr1a gene knockout mice $[$ mdr1a $(-/-)]$. Data mean \pm SEM of four to seven rats.

\section{Utilization of BBB carrier-mediated transport systems to prevent CNS side effects of nonsedative $\mathrm{H}_{1}$ antagonists}

There are many cationic drugs that are effective or toxic in the CNS. At present, the molecular characteristics of the transporters for cationic drugs are not fully established, so the results of membrane physiological studies on cationic drug transport at the BBB are summarized in this review. Transport mechanisms across the BBB may include carrier mediated processes using some types of organic cation transporters including OCTNs in parallel with passive diffusion for lipophilic cationic drugs. Among $\mathrm{H}_{1}$ antagonists, there are several derivatives that exhibit a sedative side effect, whereas such an effect by pravastatin is negligible. Differential distribution into the brain may explain the differences of CNS effects.

In previous studies, we found that mepyramine was transported into the brain via a carrier-mediated mechanism. ${ }^{61,62}$ A classical $\mathrm{H}_{1}$ antagonist, mepyramine is taken up by brain capillary endothelial cells via a saturable mechanism that is inhibitable by chlorpheniramine, diphenhydramine, and other cationic compounds, whereas choline, hemicholinium-3, or anionic drugs showed no effect. Other $\mathrm{H}_{1}$ antagonists such as cyproheptadine, ketotifen, emedastine, and azelastine (see the chemical structures in FIG. 1) are also likely to be taken up by a common mechanism, based on the observed mutual inhibitory effects. However, the inhibitory potency of cetiridine was the lowest among them. ${ }^{63} \mathrm{Be}-$ cause cetiridine has a carboxylic acid moiety within the molecule, it is a zwitterionic derivative. Accordingly, $\mathrm{H}_{1}$ antagonists, which carry only cationic charges, have higher affinity for the responsible transporter and zwitterionic derivatives seem to have lower affinity, resulting in less effect on the CNS. ${ }^{63}$ To avoid the sedative effect of $\mathrm{H}_{1}$ antagonists, it may therefore be advantageous for them to carry anionic charge. The transporter responsible for mepyramine uptake showed lower affinity for zwitterionic $\mathrm{H}_{1}$ antagonists such as cetirizine than for cationic derivatives such as ketotifen and cyproheptadine. Accordingly, we postulated that zwitterionic $\mathrm{H}_{1}$ antagonists could exhibit lower distribution to the brain. ${ }^{61-63}$

Recently, Cvetkovic et al. ${ }^{64}$ studied the cellular uptake and efflux mechanisms of a nonsedating antihistamine, fexofenadine, which is a metabolite of cationic and sedating terfenadine, and identified organic anion-transporting polypeptides (oatp) and P-glycoprotein as uptake and efflux transporters, respectively. Because tefenadine and ebastine are structurally similar to the classical $\mathrm{H}_{1}$ antagonists as shown in Figure 1, they may be transported into the brain via the same system as that suggested for mepyramine uptake. However, ebastine does not exhibit sedative properties in a practical antihistaminic dose-range.$^{65}$ Ebastine is rapidly metabolized to an active zwitterionic metabolite, carebastine, in both experimental animals and human. ${ }^{65}$ Carebastine also has a high and selective $\mathrm{H}_{1}$ receptor antagonistic activity ${ }^{66}$ and is considered to be a major contributor to the activity of the parent drug. The intestinal absorption, distribution, metabolism, and excretion of ebastine and carebastine have been studied in rats. ${ }^{63}$ Carebastine showed a limited distribution to the brain. ${ }^{67}$

The steady-state uptake of $\left[{ }^{14} \mathrm{C}\right]$ carebastine by P-glycoprotein-overexpressing K562/ADM cells was significantly lower than that by the parental drug-sensitive cell line $\mathrm{K} 562$, and that by primary cultured bovine brain capillary endothelial cells (bovine BCECs) was increased in the presence of nonlabeled carebastine and verapamil. The initial uptake of $\left[{ }^{3} \mathrm{H}\right]$ mepyramine by bovine BCECs and RBEC1 was strongly inhibited by ebastine, whereas zwitterionic carebastine was slightly inhibitory. As shown in Figure 2, the values of brain-to-plasma unbound concentration ratio $(\mathrm{Kp}, \mathrm{f})$ in $m d r l a(-/-)$ mice were increased 5.8-fold and 9.0-fold for $\left[{ }^{14} \mathrm{C}\right]$ ebastine and for $\left[{ }^{14} \mathrm{C}\right]$ carebastine, respectively, compared with those in mdrla $(+/+)$ mice. $^{68}$ From these observations, carebastine was shown to be a substrate for P-glycoproteinmediated efflux from the brain at the BBB. The relatively low affinity of carebastine for the mepyramine transport system also limits the brain distribution of carebastine after an oral dose of ebastine. ${ }^{64}$

\section{Other drugs}

Clonidine, an activator of $\alpha-2$ adrenergic receptor, was reported to be taken up by cultured porcine brain capillary endothelial cells via a carrier-mediated mechanism with a $\mathrm{Km}$ of $1.34 \mathrm{~mm}$, in a $\mathrm{pH}$-dependent manner. ${ }^{69}$ However, permeation of clonidine across the BBB is not high regardless of the participation of a transporter, perhaps due to trapping in the cells and/or the involvement of an efflux transporter other than P-gp. 
Fentanyl, a $\mu$-opiate agonist, is effective in the CNS. Its transport across the BBB may be mediated by a transporter with an apparent $\mathrm{Km}$ of $3.2 \mu \mathrm{M}$ and is inhibitable by verapamil, although the functional characteristics have not been clarified yet. ${ }^{70}$ Interestingly, although fentanyl may be effluxed by P-gp, its brain distribution is high. High BBB distribution in spite of the participation of an efflux transporter may be explained by higher efficiency of the influx transporter than that of the efflux one. So, it is possible that multiple influx and efflux transporters are involved in fentanyl transport at the $\mathrm{BBB}^{70}$ as observed for $\mathrm{H}_{1}$ antagonists. The in vivo uptake of pentazocine, a narcotic-antagonist analgesic, by rat brain was significantly inhibited by lidocaine, imipramine and propranolol, as well as by $\mathrm{H} 1$ antagonists such as mepyramine and diphenhydramine. ${ }^{71}$ Pentazocine, in spite of efflux transport by P-glycoprotein at the $\mathrm{BBB}$, is also highly distributed into brain by a carriermediated transport system that may widely recognize cationic drugs. ${ }^{72}$

\section{Peptides}

Some small-peptide transport systems other than PepT1, PepT2, and HPT expressed in the intestinal and renal epithelial cells have been suggested to exist at the BBB..$^{7,74}$

Enkephalins were demonstrated to be taken up efficiently into the brain, and the involvement of a saturable mechanism for the transport of leucine enkephalin was shown by the in situ vascular brain perfusion technique. ${ }^{73,74}$ Several other peptides, thyrotropin-releasing hormone, ${ }^{75}$ arginine-vasopressin, ${ }^{76}$ Peptide-T, ${ }^{77} \alpha$-melanocyte-stimulating hormone ${ }^{78}$ and $\delta$ sleep-inducing peptide, ${ }^{79}$ have been shown to cross the BBB and some of them showed saturable uptake, suggesting participation of carrier-mediated transport. The peptide transport mechanisms involved are classified as peptide transport systems PTS- 1 to $-5,{ }^{73,74}$ although these transporter proteins have not been isolated as yet. Recent findings ${ }^{80}$ indicated that OATP-A (SLC21A3) plays an important role in carrier-mediated transport of opioid peptides, such as [D-penicillamine-2,5] enkephalin and deltorphin II, across the BBB.

Brain uptake of glutathione, a tripeptide, measured by the BUI method showed saturation with a $\mathrm{Km}$ value of $5.8 \mathrm{~mm}$, and is specific for the reduced form of glutathione, GSH. ${ }^{81,82}$ Significant transport of GSH in intact form was also demonstrated by the brain perfusion method. ${ }^{83}$ When mRNA obtained from brain capillaries was injected into oocytes, GSH transport activity, via both sodium-dependent and -independent mechanisms, was observed with a $\mathrm{Km}$ for sodium-dependent transport of $0.4 \mathrm{~mm}$, demonstrating that the transporter protein is present at the BBB. ${ }^{84}$ Furthermore, cultured MBEC4, a model cell line for mouse brain capillary endothelial cells, exhibited sodium-dependent transport activity for GSH in a fraction rich in apical membrane. ${ }^{85}$ These observations suggest that GSH is transported in the blood-to-brain direction by a specific sodium-dependent transporter, as well as a sodium-independent one.

Toyobuku et al..$^{86}$ examined the feasibility of heterologous transduction of a transporter gene to the BBB. As peptides have multiple biological actions in the brain, they are potentially valuable as neuropharmaceuticals in the treatment of various disorders, such as Alzheimer's disease and depression. Delivery of peptide drugs to the brain, however, is a major challenge, because distribution of peptides to the brain is generally very low owing to the presence of the BBB. Toyobuku et al. ${ }^{86}$ constructed a recombinant adenovirus vector encoding PEPT1 and transduced the transporter into the BBB of rats by carotid artery injection of the vector. Heterologous expression of PEPT1 at the BBB successfully increased the brain distribution of a model substrate, cefadroxil, of PEPT1. ${ }^{86}$ Malignant gliomas are the most common primary neoplasms of the CNS. The prognosis for high-grade malignant gliomas remains bleak; survival is generally less than 1 year. Because bestatin, the substrate for PEPT1, was reported to induce apoptosis in glioma cells, ${ }^{87}$ this system may be applicable to the treatment of malignant glioma.

\section{CONCLUSIONS}

Clarification of the transport mechanisms of drugs across the BBB is important to improve the efficacy of CNS-active drugs or to reduce the CNS toxicity of drugs that are active in peripheral tissues. Recent molecular identification and functional analyses of carrier-mediated transport systems for drugs, as well as endogenous compounds, at the BBB show that brain capillary endothelial cells are equipped with various membrane transport mechanisms in both blood-to-brain (influx) and brain-toblood (efflux) directions to maintain homeostasis. In addition to the transport mechanisms covered in the present review, there must be other influx transport processes. Accordingly, utilization of influx transporters is expected to be useful in delivering many kinds of hydrophilic drugs into the brain. Furthermore, like eliminating organs such as liver and kidney, the BBB contains multiple efflux transporters, including P-gp and MRP or related transporters. Because various drugs are excluded from the brain by such transporters, prevention of efflux transport by the use of specific inhibitors is also an attractive approach to improve the brain distribution of drugs. It is essential to identify all the transporters and to characterize them functionally to provide a basis for strategies to regulate drug disposition in the brain. 


\section{REFERENCES}

1. Smith QR, Stoll J Blood-brain barrier amino acid transport. In: Introduction to the blood-brain barrier (Pardridge WM, ed), pp 188-197. Cambridge, UK: Cambridge University Press, 1998.

2. Christensen HN. Role of amino acid transport and countertransport in nutrition and metabolism. Physiol Rev 70:43-77, 1990.

3. Nutt JG, Woodward WR, Hammerstad JP, Carter JH, Anderson JL. The "ON-OFF" phenomenon in Parkinson's disease. Relation to levodopa absorption and transport. N Engl J Med 310:483-488, 1984.

4. Kanai Y, Segawa H, Miyamoto K, Uchino H, Takeda E, Endou H. Expression cloning and characterization of a transporter for large neutral amino acids activated by the heavy chain of 4F2 antigen (CD98). J Biol Chem 273:23629-23632, 1998.

5. Mastroberardino L, Spindler B, Pfeiffer R, Skelly PJ, Loffing J, Shoemaker $\mathrm{CB}$ et al. Amino acid transport by heterodimers of 4F2hc/CD98 and members of a permease family. Nature 395:288291, 1998.

6. Boado RJ, Li JY, Nagaya M, Zhang C, Pardridge WM. Selective expression of the large neutral amino acid transporter at the bloodbrain barrier. Proc Natl Acad Sci USA 12:96:12079-12084, 1999.

7. Boado RJ, Li JY, Pardridge WM. Site-directed mutagenesis of rabbit LAT1 at amino acids 219 and 234. J Neurochem 84:13221323, 2003.

8. Pineda M, Fernandez E, Torrents D, Estevez R, Lopez C, Camps $\mathrm{M}$, et al. Identification of a membrane protein, LAT-2, that coexpresses with 4F2 heavy chain, an L-type amino acid transport activity with broad specificity for small and large zwitterionic amino acids. J Biol Chem 274:19738-19744, 1999.

9. Segawa H, Fukasawa Y, Miyamoto K, Takeda E, Endou H, Kanai Identification and functional characterization of $\mathrm{a} \mathrm{Na}^{+}$-independent neutral amino acid transporter with broad substrate selectivity. J Biol Chem 274:19745-19751, 1999.

10. Kido Y, Tamai I, Uchino H, Sai Y, Suzuki F, Tsuji A. Molecular and functional identification of large neutral amino acid transporters LAT1 and LAT2 and their pharmacological relevance at the blood-brain barrier. J Pharm Pharmcol 53:497-503, 2001.

11. Pardridge WM. Brain metabolism: a perspective from the bloodbrain barrier. Physiol Rev 63:1481-1535, 1983.

12. Nishizaki T, Kammesheidt A, Sumikawa K, Asada T, Okada Y. A sodium- and energy-dependent glucose transporter with similarity to SGLT1-2 is expressed in bovine cortical vessels. Neurosci Res 22:13-22, 1995.

13. Kumagai AK, Dwyer KJ, Pardridge WM. Differential glycosylation of the GLUT1 glucose transporter in brain capillaries and choroid plexus. Biochim Biophys Acta 91:1193:24-30, 1994.

14. Halmos T, Santarromana M, Antonakis K, Scherman D. Synthesis of O-methylsulfonyl derivatives of D-glucose as potential alkylating agents for targeted drug delivery to the brain. Evaluation of their interaction with the human erythrocyte GLUT1 hexose transporter. Carbohyd Res 299:15-21, 1997.

15. Negri L, Lattanzi R, Tabacco F, Scolaro B, Rocchi R. Glycodermorphins: opioid peptides with potent and prolonged analgesic activity and enhanced blood-brain barrier penetration. Br J Pharmacol 124:1516-1522, 1998.

16. Gerhart DZ, Enerson BE, Zhdankina OY, Leino RL, Drews LR. Expression of monocarboxylate transporter MCT1 by brain endothelium and glia in adult and suckling rats. Am J Physiol (Lond) 273:E207-E213, 1997.

17. Kido Y, Tamai I, Okamoto M, Suzuki F, Tsuji A. Functional clarification of MCT1-mediated transport of monocarboxylic acids at the blood-brain barrier of rats using in vivo cultured cells and in vivo BUI studies. Pharm Res 17:55-62, 2000.

18. Oldendolf WH. Blood-brain barrier permeability of lactate. Eur Neurol 6:49-55, 1971.

19. Oldendolf WH. Carrier-mediated blood-brain barrier transport of short-chain monocarboxylic organic acids. Am J Physiol (Lond) 224:1450-1453, 1973.

20. Nemoto EM, Severinghaus JW. Stereopecfic permeability of rat blood-brain barrier to lactic acid. Stroke 5:81-84, 1997.

21. Kang YS, Terasaki T, Tsuji A. Acidic drug transport in vivo through the blood-brain barrier: a role of the transport carrier for monocarboxylic acids. J Pharmacobiodyn 13:158-163, 1990.

22. Terasaki T, Kang YS, Ohnishi T, Tsuji A. In-vitro evidence for carrier-mediated uptake of acidic drugs by isolated bovine brain capillaries. J Pharm Pharmacol 43:172-176, 1991.

23. Terasaki T, Takakuwa S, Moritani S, Tsuji A. Transport of monocarboxylic acids at the blood-brain barrier: studies with monolayers of primary cultured bovine brain capillary endothelial cells. J Pharmacol Exp Ther 258:932-937, 1991.

24. Enerson B, Drewes LR. Molecular features, regulation, and function of monocarboxylate transporters: implications for drug delivery. J Pharm Sci 92:1531-1544, 2003.

25. Tamai I, Sai Y, Ono A, Kido Y, Yabuuchi H, Takanaga H, et al. Immunohistochemical and functional characterization of $\mathrm{pH}$-dependent intestinal absorption of organic weak acids by monocarboxylic acid transporter MCT1. J Pharm Pharmacol 51:113-1121, 1999.

26. Garcia CK, Goldstein JL, Oathak RK, Anderson RG, Brown MS. Molecular characterization of a membrane transporter for lactate, pyruvate, and other monocarboxylates: implications for the Cori cycle. Cell 76:865-873, 1994

27. Deguchi Y, Nozawa K, Yamada S, Yokoyama Y Kimura R. Quantitative evaluation of brain distribution and blood-brain barrier efflux transport of probenecid in rats by microdialysis: possible involvement of the monocarboxylic acid transport system. J Pharmacol Exp Ther 280:551-560, 1997.

28. Deguchi Y, Yokoyama Y, Sakamoto T, Hayashi H, Naito T, Yamada $S$, et al. Brain distribution of 6-mercaptopurine is regulated by the efflux transport system in the blood-brain barrier. Life Sci 66:649-662, 2000.

29. Sun H, Dai H, Shaik N, Elmquist WE. Drug efflux transporters in the CNS. Adv Drug Deliv Rev 55:83-105, 2003.

30. Cornford EM, Diep CP, Pardridge WM. Blood-brain barrier transport of valproic acid. J Neurochem 44:1541-1550, 1985.

31. Adkison KDK, Shen DD. Uptake of valproic acid into rat brain is mediated by a medium-chain fatty acid transporter. $J$ Pharmacol Exp Ther 276:1189-1200, 1996.

32. Sekine T, Watanabe T, Hosoyamada M, Kanai Y, Endou H. Expression cloning and characterization of a novel multispecific organic anion transporter. J Biol Chem 272:18526-18529, 1997.

33. Sekine T, Cha SH, Endou $\mathrm{H}$. The multispecific organic anion transporter (OAT) family. Eur J Physiol (Lond) 400:337-350, 2000.

34. Sekine T, Cha SH, Endou H. The multispecific organic anion transporter (OAT) family. Pflugers Arch-Eur J Physiol (Lond) 440:337-350, 2000.

35. Gao B, Stieger B, Now B, Fritschy JM, Meier PJ. Localization of the organic anion transporting polypeptide 2 (Oatp2) in capillary endothelium and choroid plexus epithelium of rat brain. $J$ Histochem Cytochem 47:1255-1264, 1999.

36. Hagenbuch B, Gao B, Meier PJ. Transport of xenobiotics across the blood-bran barrier. News Physiol Sci 17:231-234, 2002.

37. Kusuhara H, Sekine T, Utsunomiya-Tate N, Tsuda M, Kojima R, Sugiyama Y, Kanai K, Endou H. Molecular cloning and characterization of a new multispecific organic anion transporter from rat brain. J Biol Chem 274:13675-13680, 1999.

38. Tamai I, Nezu J, Uchino H, Sai Y, Oku A, Shimane M, et al. Molecular identification and characterization of novel members of the human organic anion transporter (OATP) family. Biochem Biophys Res Commun 273:251-260, 2000.

39. Tamai I, Nozawa T, Koshida M, Nezu J, Sai Y, Tsuji A. Functional characterization of human organic anion transporting polypeptide OATP-B in comparison with liver-specific OATP-C. Pharm Res $18: 1262-1269,2001$

40. Gao B, Vavricha S, Huber RD, Meier PJ. Differential cellular localization of organic anion transporting polypeptides in human brain and retina. PharmConference, Abstract P12, Pontresina, Switzerland, 2003.

41. Kobayashi D, Nozawa T, Imai K, Nezu J, Tsuji A, Tamai I Involvement of human organic anion transporting polypeptide OATP-B (SLC21A9) in pH-dependent transport across intestinal apical membrane. J Pharmacol Exp Ther 306:703-708, 2003.

42. Nozawa T, Imai K, Nezu J, Tsuji A, Tamai I. Functional charac- 
terization of $\mathrm{pH}$-sensitive organic anion transporting polypeptide OATP-B in human. J Pharmacol Exp Ther 308:438-445, 2004.

43. Tsuji A, Saheki A, Tamai I, Terasaki T. Transport mechanism of 3-hydroxy-3-methylglutaryl coenzyme A reductase inhibitors at the blood-brain barrier. J Pharmacol Exp Ther 267:1085-1090, 1993.

44. Saheki A, Terasaki T, Tamai I, Tsuji A. In vivo and in vitro blood-brain barrier transport of 3-hydroxy-3-methylglutaryl coenzyme A (HMG-CoA) reductase inhibitors. Pharm Res 11:305-311, 1994.

45. Zhang L, Brett CM, GiacoMmini KM. Role of organic cation transporters in drug absorption and elimination. Anпи Rev Pharmacol Toxicol 38:431-460, 1998.

46. Busch AE, Karbach U, Miska D, Gorboulev V, Akhoundova A, Volk $\mathrm{C}$, et al. Human neurons express the polyspecific cation transporter hOCT2, which translocates monoamine neurotransmitters, amantadine, and memantine. Mol Pharmacol 54:342-352, 1998.

47. Wu X, Kekuda R, Huang W, Fei Y-J, Leibach FH, Chen J, et al. Identity of the organic cation transporter OCT3 as the extraneuronal monoamine transporter and evidence for the expression of the transporter in the brain. J Biol Chem 273:32776-32786, 1998.

48. Tamai I, Yabuuchi H, Nezu J, Sai Y, Oku A, Shimane M, et al. Cloning and characterization of a novel human $\mathrm{pH}$-dependent organic cation transporter, OCTN1. FEBS Lett 419:107-111, 1997.

49. Tamai I, Ohashi R, Nezu JI, Sai Y, Kobayashi D, Oku A, Shimane $\mathrm{M}$, Tsuji A. Molecular and functional characterization of organic cation/carnitine transporter family in mice. $J$ Biol Chem 275:40064-40072, 2000.

50. Tamai I, Ohashi R, Nezu J, Yabuuchi H, Oku A, Shimane M, et al. Molecular and functional identification of sodium ion-dependent high affinity human carnitine transporter OCTN2. J Biol Chem 273:20378-20382, 1998.

51. Sekine T, Kusuhara H, Utsunomia-Tate N, Tsuda M, Sugiyama Y, Kanai Y, et al. Molecular cloning and characterization of highaffinity carnitine transporter from rat intestine. Biochem Biophys Res Commun 251:586-591, 1998.

52. Nezu J, Tamai I, Oku A, Ohashi R, Yabuuchi H, Hashimoto N, et al. Primary systemic carnitine deficiency is caused by mutations in a sodium-ion dependent carnitine transporter OCTN2. Nat Genet 21:91-94, 1999.

53. Peltekova VD, Wintle RF, Rubin LA, Amos CI, Huang Q, Gu X, et al. Functional variants of OCTN cation transporter genes are associated with Crohn disease. Nat Genet 36:471-475, 2004.

54. Yabuuchi H, Tamai I, Nezu J, Sakamoto K, Oku A, Shimane M, et al. Novel membrane transporter OCTN1 mediates multispecific, bidirectional, and $\mathrm{pH}$-dependent transport of organic cations. J Pharmacol Exp Ther 289:768-773, 1999.

55. Wu X, Prasado PD, Leibach FH, Ganapathy V. cDNA sequence, transport function, and geneomic organization of human OCTN2, a new member of the organic cation transporter family. Biochem Biophy Res Commun 246:589-595, 1998.

56. Wu X, Huang W, Prasado PD, Seth P, Rajan DP, Leibach FH, et al. Functional characterization and tissue distribution pattern of organic cation transporter 2 (OCTN2), an organic cation/carnitine transporter. J Pharmacol Exp Ther 290:1482-1492, 1999.

57. Ohashi R, Tamai I, Yabuuchi H, Nezu JI, Oku A, Sai Y, Shimane $\mathrm{M}$, Tsuji A. $\mathrm{Na}(+)$-dependent carnitine transport by organic cation transporter (OCTN2): its pharmacological and toxicological relevance. J Pharmacol Exp Ther 291:778-784,1999.

58. Ohashi R, Tamai I, Nezu J, Nikaido H, Hashimoto N, Oku A, et al. Molecular and physiological evidence for multifunctionality of carnitine/organic cation transporter OCTN2. Mol Pharmacol 59: 358-366, 2001.

59. Friedrich A, Prasasd PD, Freyer D, Ganapathy V, Brust P. Molecular cloning and functional characterization of the OCTN2 transporter at the RBE4 cells, an in vitro model of the blood-brain barrier. Brain Res 968:69-79, 2003.

60. Inano A, Sai Y, Nikaido H, Hasimoto N, Asano M, Tsuji A. Acetyl-L-carnitine permeability across the blood-brain barrier and involvement of carnitine transporter OCTN2. Biopharm Drug Dispos 24: 357-365, 2003.

61. Yamazaki M, Fukuoka H, Nagata O, Kato H, Ito Y, Terasaki T,
Tsuji A. Transport mechanism of an $\mathrm{H}_{1}$-antagonist at the bloodbrain barrier: transport mechanism of mepyramine using carotid injection technique. Biol Pharm Bull 17:676-679, 1994.

62. Yamazaki M, Terasaki T, Yoshioka K, Nagata O, Kato H, Ito Y, et al. Carrier-mediated transport of $\mathrm{H}_{1}$-antagonist at the bloodbrain barrier: mepyramine uptake into bovine brain capillary endothelial cells in primary monolayer cultures. Pharm Res 11:975978, 1994.

63. Yamazaki M, Terasaki T, Yoshioka K, Nagata O, Kato H, Ito Y, et al. Carrier-mediated transport of $\mathrm{H}_{1}$-antagonist at the bloodbrain barrier: a common transport system of $\mathrm{H}_{1}$-antagonists and lipophilic basic drugs. Pharm Res 11:1516-1518, 1994.

64. Cvetkovic M, Leake B, Fromm MF, Wilkinson GR, Kim RB. OATP and P-glycoprotein transporters mediate the cellular uptake and excretion of fexofenadine. Drug Metab Dispos 27:866-871, 1999.

65. Vincent J, Liminana R, Meredith PA, Reid JL. The pharmacokinetics, antihistamine and concentration-effect relationship of ebastine in healthy subjects. Br J Clin Pharmacol 26:497-502, 1998.

66. Matsuda M, Sakashita M, Mizuki Y, Yamaguchi T, Fujii T, Sekine Y. Comparative pharmacokinetics of the histamine H1-receptor antagonist ebastine and its active metabolite carebastine in rats, guinea pigs, dogs and monkeys. Arzneim-Forsch/Drug Res 44:5559, 1994.

67. Yamaguchi T, Hashizume T, Matsuda M, Sakashita M, Fujii T, Sekine Y, et al. Pharmacokinetics of the H1-receptor antagonist ebastine and its active metabolite carebastine in healthy subjects. Arzneimittelforschung 44:59-64, 1994

68. Tamai I, Kido Y, Yamashita J, Sai Y, Tsuji A. Blood-brain barrier transport of $\mathrm{H}_{1}$-antagonist ebastine and its metabolite carebastine. J Drug Target 8:383-393, 2000.

69. Huwyler J, Fricker G, Torok M, Schneider M, Drewe J. Transport of clonidine across cultured brain microvessel endothelial cells. J Pharmacol Exp Ther 282:81-85, 1997.

70. Henthorn TK, Liu Y, Mahapatro M, Ng KY. Active transport of fentanyl by the blood-brain barrier. J Pharmacol Exp Ther 289: 1084-1089, 1999.

71. Suzuki T, Moriki Y, Goto H, Tomono K, Hanano M, Watanabe $\mathrm{J}$. Investigation on the influx transport mechanism of pentazocine at the blood-brain barrier in rats using the carotid injection technique. Biol Pharm Bull 25:1351-1355, 2002.

72. Moriki Y, Suzuki T, Fukami T, Hanano M, Tomono K, Watanabe J. Involvement of P-glycoprotein in blood-brain barrier transport of pentazocine in rats using brain uptake index method. Biol Pharm Bull 27:932-935, 2004.

73. Banks WA, Audus K, Davis TP. Permeability of the blood-brain barrier to peptides: an approach to the development of therapeutically useful analogs. Peptides 13:1289-1294, 1992.

74. Begley DJ. The blood-brain barrier: principle for targeting peptides and drugs to the central nervous system. J Pharm Pharmacol 48:136-146, 1996.

75. Zlokovic, BV, Lipovac MN, Begley DJ, Davson H, Rakic L. Slow penetration of thyrotropine-releasing hormone across the bloodbrain barrier of an in situ perfused guinea pig brain. $J$ Neurochem 51:252-257, 1988.

76. Zlokovic BV, Hyman S, McComb JG, Lipovac MN, Tang G, Davson H. Kinetics of arginine-vasopressin uptake at the bloodbrain barrier. Biochim Biophys Acta 1025:191-198, 1990.

77. Barrera CM, Kastin AJ, Banks WA. D-[Ala1]-peptide T-amide is transported from blood to brain by saturable system. Brain Res Bull 19:629-633, 1987.

78. Wilson JF. Low permeability of the blood-brain barrier to nanomolar concentrations of immunoreactive $\alpha$-melanotropin. Psychopharmacol 96:262-266, 1988.

79. Banks WA, Kastin AJ, Coy DH. Evidence that ${ }^{125} \mathrm{I}-\mathrm{N}-\mathrm{Tyr}-\delta$ sleeping peptide crosses the blood-brain barrier by a noncompetitive mechanism. Brain Res 301:201-207, 1984.

80. Gao B, Hagenbuch B, Kullak-Ublick GA, Benke D, Aguzzi A, Meier PJ. Organic anion-transporting polypeptides mediate transport of opioid peptides across blood-brain barrier. J Pharmacol Exp Ther 294:73-79, 2000.

81. Kannan R, Kuhlenkamp JF, Jeandidier E, Trinh H, Ookhtens M, Kaplowitz N. Evidence for carrier-mediated transport for glutathi- 
one across the blood-brain barrier in the rat. Am J Physiol (Lond) 259:E1-E10, 1990.

82. Kannan R, Kuhlenkamp JF, Ookhtens M, Kaplowitz N. Transport of glutathione at the blood-brain barrier of the rat: inhibition by glutathione analogues and age-dependence. J Pharmacol Exp Ther 263:964-970, 1992.

83. Zlokovic BV, Mackic JB, McComb JG, Weiss MH, Kaplowitz N, Kannan R. Evidence for transcapillary transport of reduced glutathione in vascular perfused guinea-pig brain. Biochem Biophys Res Commun 201:402-408, 1994.

84. Kannan R, Yi JR, Tang D, Li Y, Zlokovic BV, Kaplowitz N. Evidence for the existence of a sodium-dependent glutathione (GSH) transporter. Expression of bovine brain capillary mRNA and size fractions in Xenopus laevis oocytes and dissociation from $\gamma$-glutamyltranspeptidase and facilitative GSH transporters. $J$ Biol Chem 271:9754-9758, 1996.

85. Kannan R, Mittur A, Bao Y, Tsuruo T, Kaplowitz N. GSH transport in immortalized mouse brain endothelial cells: evidence for apical localization of a sodium-dependent GSH transporter. $\mathrm{J} \mathrm{Neu}$ rochem 73:390-399, 1999.

86. Toyobuku H, Sai Y, Kagami T, Tamai I, Tsuji A. Delivery of peptide drugs to the brain by adenovirus-mediated heterologous expression of human oligopeptide transporter at the blood-brain barrier. J Pharmacol Exp Ther 305:40-47, 2003.

87. Schlapbach R, Fontana, A. Differential activity of bcl-2 and ICE enzyme family protease inhibitors on Fas and puromycin-induced apoptosis of glioma cells. Biochim Biophys Acta 1359:174-180, 1997. 